\title{
Lifetime extension of humpback whale skin fibroblasts and their response to lipopolysaccharide (LPS) and a mixture of polychlorinated biphenyls (Aroclor)
}

\author{
Michael Burkard • Susan Bengtson Nash • \\ Gessica Gambaro • Deanne Whitworth • \\ Kristin Schirmer (1)
}

Received: 27 June 2018 / Accepted: 18 December 2018 / Published online: 10 January 2019

(C) The Author(s) 2019

\begin{abstract}
Marine mammals, such as whales, have a high proportion of body fat and so are susceptible to the accumulation, and associated detrimental health effects, of lipophilic environmental contaminants. Recently, we developed a wild-type cell line from humpback whale fibroblasts (HuWa). Extensive molecular
\end{abstract}

Electronic supplementary material The online version of this article (https://doi.org/10.1007/s10565-018-09457-1) contains supplementary material, which is available to authorized users.

M. Burkard $\cdot$ S. Bengtson Nash

School of Environment and Science, Griffith University, Brisbane, QLD, Australia

M. Burkard · G. Gambaro · K. Schirmer $(\bowtie)$

Swiss Federal Institute of Aquatic Science and Technology

(Eawag), Überlandstrasse 133, CH-8600 Dübendorf, Switzerland

e-mail: Kristin.Schirmer@ eawag.ch

D. Whitworth

School of Veterinary Science, The University of Queensland,

Gatton, QLD, Australia

D. Whitworth

Australian Institute for Bioengineering and Nanotechnology, The University of Queensland, St Lucia, QLD, Australia

K. Schirmer

Institute of Biogechemistry and Pollutant Dynamics, ETH Zürich, Zürich, Switzerland

K. Schirmer

School of Architecture, Civil and Environmental Engineering,

EPF Lausanne, Lausanne, Switzerland assessments with mammalian wild-type cells are typically constrained by a finite life span, with cells eventually becoming senescent. Thus, the present work explored the possibility of preventing senescence in the HuWa cell line by transfection with plasmids encoding the simian virus large T antigen (SV40T) or telomerase reverse transcriptase (TERT). No stable expression was achieved upon SV40 transfection. Transfection with TERT, on the other hand, activated the expression of telomerase in HuWa cells. At the time of manuscript preparation, the transfected HuWa cells $\left(\mathrm{HuWa}_{\mathrm{TERT}}\right)$ have been stable for at least 59 passages post-transfection. HuWa $\mathrm{T}_{\mathrm{TERT}}$ proliferate rapidly and maintain initial cell characteristics, such as morphology and chromosomal stability. The response of $\mathrm{HuWa}_{\mathrm{TERT}}$ cells to an immune stimulant (lipopolysaccharide (LPS)) and an immunotoxicant (Aroclor1254) was assessed by measurement of intracellular levels of the pro-inflammatory cytokines interleukin (IL)-6, IL-1 $\beta$ and tumour necrosis factor (TNF)- $\alpha$. HuWa $\mathrm{TERT}_{\text {TEl }}$ cells constitutively express IL-6, IL-1 $\beta$ and TNF $\alpha$. Exposure to neither LPS nor Aroclor1254 had an effect on the levels of these cytokines. Overall, this work supports the diverse applicability of HuWa cell lines in that they display reliable long-term preservation, susceptibility to exogenous gene transfer and enable the study of humpback whale-specific cellular response mechanisms.

Keywords Cell line transfection · Humpback whale . Megaptera novaeangliae $\cdot$ Immunotoxicity .

Inflammatory cytokines $\cdot$ Relative telomerase activity 


\section{Introduction}

Long-lived cetaceans, such as humpback whales (Megaptera novaeangliae), are continuously exposed to lipophilic and bioaccumulative environmental contaminants. The migratory and fasting life history behaviour of this species results in seasonal remobilisation of these toxicants (Bengtson Nash et al. 2013). Further, the timing of elevated circulating contaminant levels coincides with early stages of pregnancy and nursing of new-born calves, intensifying associated toxicological risk (Bengtson Nash 2018). To date, there is little information regarding the toxicological sensitivity of the species (Bengtson Nash et al. 2014; Waugh et al. 2011), and no information specifically related to the influence of contaminants on the immune health of humpback whales; studies are limited to postmortem examination (Apprill et al. 2014; Holyoake et al. 2012) precluding controlled experimentation. Thus, suitable approaches for the quantitative evaluation of speciesspecific toxicological and immune-toxicological risks in cetaceans are urgently needed; in vitro approaches present one option for the elucidation of toxicological hazards and molecular responses to different stressors at the cellular level.

Recently, we established a wild-type cell line from humpback whale skin (HuWa) (Burkard et al. 2015), which we designated $\mathrm{HuWa}_{\text {wild-type }}$ for the purpose of the current study. The long-term survival of $\mathrm{HuWa}_{\text {wild-type }}$ is unknown. Mammalian cells generally undergo only a limited number of proliferation cycles (40-60) until cells enter an irreversible state of growth arrest and senescence known as the Hayflick limit (Hayflick 1965; Nakagawa and Opitz 2007). Consequently, various transfection strategies have been developed to introduce foreign DNA into mammalian wild-type cells in order to control the cell cycle and cellular senescence. One commonly applied transfection strategy is expression of the simian virus 40 large $\mathrm{T}$ antigen (SV40T), which is expressed upon infection with the polyomavirus SV40. Expression of SV40T antigen inactivates tumour suppressor genes, such as $p 53$ and the $\mathrm{Rb}$ family, and therefore enables continuous mitosis and long-term survival (Ali and DeCaprio 2001; Ahuja et al. 2005; Wright and Shay 1992).

Another approach to overcoming cellular senescence is by preventing telomere shortening (Wright et al. 1989). Telomeres, which are located at the end of eukaryotic chromosomes, contain a series of nucleotide sequences; loss of these leads to inhibition of the cell cycle, activation of tumour suppressor proteins and, ultimately, senescence (Vaziri and Benchimol 1996; Di Leonardo et al. 1994; Sherr and DePinho 2000). Telomeres are synthesised by the ribonucleoprotein telomerase, which consists of an RNA template and the catalytically active telomerase reverse transcriptase (TERT). It has been shown in human fibroblasts that, if TERT expression is activated, cells can be continuously maintained (Bodnar et al. 1998).

Over-expression of the SV40T and TERT target proteins has been performed in a wide range of mammalian cell lines; however, only a few studies report on SV40Tassociated long-term cultivation of cetacean-derived cell cultures (e.g. epithelial cells from bottlenose dolphin (Tursiops truncatus) (Pine et al. 2004; Yu et al. 2005), humpback dolphin (Sousa plumbea) fibroblasts (Jin et al. 2013) and Yangtze finless porpoise (Neophocaena phocaenoides) fibroblasts (Wang et al. 2011). No previous study has reported on TERT transfection of cells from a marine mammal.

This study aimed to firstly establish a reliable and consistently available humpback whale cell culture model as an investigative tool for further toxicological and other investigations. Secondly, the study sought to gain knowledge on the potential application of these cells for assessing immune regulation under non-stress conditions and in immune challenged or chemically stressed humpback whale cells.

To this end, HuWa $\mathrm{wild}_{\text {wype }}$ cells were transfected with plasmids containing SV40T or TERT, and successful clones were characterised regarding their growth, chromosomal stability and sub-cellular structure. Transfected HuWa cells were treated either with lipopolysaccharide (LPS) or Aroclor (polychlorinated biphenyl (PCB) mixture), and the expression of inflammatory cytokines was quantitatively assessed using antihuman antibodies. LPS is a component of gramnegative bacteria and can stimulate physiological immune reactions by expression of cytokines, chemokines and general stress markers (He et al. 2009; Alexander and Rietschel 2001). Aroclor1254 is a commercially produced PCB mixture. PCBs are ubiquitous and problematic environmental contaminants that are frequently detected in humpback whale blubber (Bengtson Nash et al. 2018; Waugh et al. 2014; Bengtson Nash et al. 2013) and which have been shown to trigger immunotoxic effects in other marine mammals (Desforges et al. 2016; Mori et al. 2008; Levin et al. 2014; Desforges et al. 2017). 


\section{Methods}

Reagents

All chemicals were ordered from Sigma-Aldrich (Buchs, Switzerland), and all cell culture ware, buffers and media from Life Technologies Invitrogen (Basel, Switzerland), unless otherwise stated. Cell culture flasks were purchased from TPP (Transadingen, Switzerland) and cell culture plates from Greiner Bio-One (Frickenhausen, Germany). Mycoplasma testing was performed approximately every 2 months using the MycoAlert detection kit (Lonza, Visp, Switzerland) and was always found to be negative.

\section{Cell culture and transfection}

The HuWa cell line was previously derived from a dermal biopsy of a free swimming male humpback whale (Burkard et al. 2015). Cells were maintained in HuWa medium, i.e. DMEM/F12 medium supplemented with $10 \%$ fetal bovine serum (FBS), $0.1 \mathrm{M}$ non-essential amino acids, $1 \mathrm{M}$ sodium pyruvate and $1 \%$ of $5.000 \mathrm{U} /$ $\mathrm{ml}$ penicillin-streptomycin, at $37^{\circ} \mathrm{C}$ and $5 \% \mathrm{CO}_{2}$. The medium was changed every second day. At $80-90 \%$ confluency, cells were passaged at a ratio of 1:3.

\section{Plasmid preparation and transfection}

Two plasmids containing SV40T (pBABE-puroSV40 LT and pCEP4-hygro-SV40-Tg) and one plasmid containing hTERT (pBABE-puro-hTERT) were purchased from Addgene (Cambridge, USA) (Table S1). Plasmids were amplified in Escherichia coli $D H 5 \alpha$ according to standard protocols, and the plasmid DNA was isolated using the Wizard SV Minipreps DNA purification system (Promega, Duebendorf, Switzerland) following the manufacturer's protocols. For transfection, HuWa1 cells (passages 8-12; Burkard et al. 2015) were plated into 6 -well cell culture plates at a density of $2.6 \times$ $10^{4}$ cells $/ \mathrm{cm}^{2}, 48 \mathrm{~h}$ prior to transfection. Two transfection reagents were tested: liposome-based Lipofectamine LTX (Thermo Fisher, Reinach, Switzerland) and non-liposomal Fugene HD (Promega, Duebendorf, Switzerland). Transfections were performed following manufacturer's protocols.

\section{Selection and cloning}

Following transfection, cells were allowed to recover for $24 \mathrm{~h}$ in HuWa medium. Subsequently, they were passaged in 6-well plates and cultured in antibiotic selection medium consisting of HuWa medium supplemented with $100 \mu \mathrm{g} / \mathrm{ml}$ hygromycin (pCEP4-hygro-SV40-Tg) or $25 \mu \mathrm{g} / \mathrm{ml}$ puromycin (pBABE-puro-SV40 LT and pBABE-puro-hTERT) (Fig. S1). Antibiotics were applied at the lowest concentration required to kill $100 \%$ of $\mathrm{HuWa}_{\text {wild-type. }}$ Antibiotic-resistant clones were observed from day 10 onwards. Individual clones were isolated using 10-mm cloning cylinders (Sigma, Saint Louis, USA) and expanded as per standard protocols.

\section{Immunocytochemistry: SV40T}

Immunocytochemical staining was used to verify SV40T expression. SV40T-transfected cells were seeded $\left(1.7 \times 10^{4}\right.$ cells $\left./ \mathrm{cm}^{2}\right)$ onto coverslips within 24-well plates. After $48 \mathrm{~h}$ of growth, cells were washed with $1 \times$ PBS, fixed with $3.7 \%$ paraformaldehyde in PBS for 20 min at RT, permeabilised in $0.2 \%$ Triton X-100 in PBS for 30 min, blocked with $4 \%$ goat serum in PBS and incubated with Image-iT® FX signal enhancer (Molecular Probes, Eugene, USA) for $20 \mathrm{~min}$. Cells were incubated with the primary antibody (mouse monoclonal to SV40T-antigen; Abcam 16879) at a dilution of $5 \mu \mathrm{g} / \mathrm{ml}$ in $1 \%$ goat serum $/ 0.05 \%$ Triton X-100 in PBS at $4{ }^{\circ} \mathrm{C}$ overnight. Subsequently, samples were washed three times with $0.05 \%$ Triton $\mathrm{X}$ in PBS and incubated with the secondary antibody (Alexa Fluor ${ }^{\circledR}$ 546 Goat Anti-Mouse IgG $(\mathrm{H}+\mathrm{L})$ ) at a dilution of $1: 1000$ in $0.05 \%$ Triton $\mathrm{X}$ in PBS for $1 \mathrm{~h}$ at RT. 4',6Diamidin-2-phenylindol (DAPI) was used for nuclear staining and applied before mounting under coverslips with ProLong Antifade (Molecular Probes, Eugene, USA). The vimentin cytoskeleton was visualised by simultaneously immunostaining with a rabbit monoclonal antibody to vimentin (Abcam ab92547, 1:500; secondary antibody Alexa Fluor® 488 Goat Anti-Rabbit IgG $(\mathrm{H}+\mathrm{L}), 1: 1000)$.

\section{Telomerase activity}

Telomerase activity was assessed using TeloTAGGG Telomerase PCR ELISA (Roche, Mannheim, Germany) following the manufacturer's protocol. In brief, $2 \times 10^{5}$ $\mathrm{HuWa}_{\mathrm{TERT}}$ cells were harvested and lysed, and 
telomeric repeat amplification was performed with provided substrate primers (20-min elongation, 5-min inactivation and 30 amplification cycles). Products were denatured and hybridised with digoxigenin (DIG), followed by immobilisation with biotin and streptavidin coating. Samples were semi-quantitatively assessed using the internal standard and horseradish peroxidase (Anti-DIG-HRP), which is sensitive to tetramethylbenzidine (TMB). The limit of detection (LOD) was considered as the twofold background activity. The data for telomerase activity is shown for 10,000 cell equivalents.

\section{Growth curve}

$\mathrm{HuWa}_{\mathrm{TERT}}$ cells were seeded into 12 -well plates at a density of $8.5 \times 10^{3}$ cells $/ \mathrm{cm}^{2}$. Cells were counted after 1, 3, 5 and 7 days using an electronic particle counter (Casy TTC, Schaerfe System, Reutlingen, Germany). Population doubling time (PDT) was calculated from the log phase of the growth curve using the following formula: $\mathrm{PDT}=\log 2 /\left(\log \mathrm{N}_{2}-\log \mathrm{N}_{1}\right) \times t$, where $\mathrm{N}_{1}=$ cell number $/ \mathrm{ml}$ at day 3 and $\mathrm{N}_{2}=$ cell number $/ \mathrm{ml}$ at day 7.

\section{Karyotype}

Two clones of HuWa $\mathrm{TERT}_{\text {at }}$ assage 26 were treated with colcemid (Invitrogen, Basel, Switzerland) and fixed with a solution of $25 \%$ acetic acid and $75 \%$ methanol as per standard protocols. A minimum of 20 metaphase spreads for each clone were analysed by Cell Guidance Systems (Cambridge, UK) using standard Gbanding procedures.

\section{Fluorescence imaging of organelles}

Cells were seeded onto coverslips at $1.7 \times 10^{4}$ cells $/ \mathrm{cm}^{2}$. After $48 \mathrm{~h}$, cells were stained with the lipophilic stain Nile Red (AAT Bioquast, Sunnyvale, CA, USA) at a ratio of 1:5000 in culture medium for $20 \mathrm{~min}$ at $37^{\circ} \mathrm{C}$. The endoplasmic reticulum was stained with ERTracker (Thermo Fisher, Reinach, Switzerland) at a ratio of 1:2000 in medium for $15 \mathrm{~min}$ at $37^{\circ} \mathrm{C}$. Nuclei were stained with NucBlue (Thermo Fisher, Reinach, Switzerland) for $15 \mathrm{~min}$ at $37{ }^{\circ} \mathrm{C}$. Cells were visualised immediately using scanning confocal microscopy (Leica, Heerbrugg, Switzerland).
Scanning electron microscopy

Cells were seeded at $1.7 \times 10^{4}$ cells $/ \mathrm{cm}^{2}$ on $12-\mathrm{mm}$ carbon-coated coverslips. Cells were washed with PBS and fixed for $1 \mathrm{~h}$ at room temperature using $2.5 \%$ glutaraldehyde. After three PBS washing steps, cell monolayers were incubated with $1 \% \mathrm{OsO}_{4}$ for $30 \mathrm{~min}$, washed again with PBS and immersed in $1 \%$ thiocarbohydrazide for $30 \mathrm{~min}$. Thereafter, cells were again incubated with $1 \% \mathrm{OsO}_{4}$ for $30 \mathrm{~min}$ and treated with $10 \%$ ionic liquid (Hitachi IL-1000) for $5 \mathrm{~min}$ followed by short dips in $\mathrm{dH}_{2} \mathrm{O}$. The coverslips were air dried and mounted onto 12-mm aluminium scanning electron microscopy (SEM) stubs with conductive carbon cement (Leit-C). Imaging was performed top down in a Helios 600i FEI focused ion beam scanning electron microscope by secondary electron detection (ETD) at $2 \mathrm{kV}$ and $0.34 \mathrm{nA}$. Cross sections were generated by gallium ion milling at $30 \mathrm{kV}$ and $790 \mathrm{pA}$ and performed on a tilted stage which was perpendicular to the cell monolayer. The images were tilt corrected for perspective distortion. SEM was performed by ScopeM (ETH Zürich, Switzerland).

Immuno-toxicological investigation

All immune stressor experiments were performed in medium containing FBS. Because FBS contains hormones and growth factors which can influence the expression of cytokines in cells, we reduced the influence of these undefined factors by performing experiments in DMEM/F12 supplemented with $1 \%$ FBS, rather than the usual $10 \%$ FBS. Cells in 1\% FBS were around $75 \%$ as metabolically active as those in 10\% FBS (Fig. S2). Before treatment, cells were seeded at a density of $2.5 \times$ $10^{4}$ cells $/ \mathrm{cm}^{2}$ in 12-well plates and cultured for 4 days until they had formed confluent monolayers, after which time they were used in the following analyses.

\section{Cell viability assessment}

Metabolic activity and membrane integrity were assessed by the fluorescent indicator dyes alamarBlue (AB) and 5-carboxyfluorescein diacetate acetoxymethyl ester (CFDA-AM) as described in Schirmer et al. (1997). Briefly, upon treatment, the medium was discarded, cells were washed once with $1 \times$ PBS and incubated for $25 \mathrm{~min}$ with $5 \%(v / v) \mathrm{AB}$ and $4 \mu \mathrm{M}$ CFDA-AM in $1 \times$ PBS at $37{ }^{\circ} \mathrm{C}$. Fluorescence was 
measured at excitation/emission wavelengths of 493/ 541 and 530/595 nm for AB and CFDA-AM, respectively (Tecan, Infinite M200, Maennedorf, Switzerland). The results were expressed as a percentage of the appropriate control, which was set to $100 \%$.

\section{Quantification of inflammatory cytokines}

The literature was systematically scanned for proteins that are expressed by fibroblasts, and the reaction of selected targets upon treatment with LPS and PCBs was reported (detailed in Table S2). The following cytokines/ chemokines were selected in order to evaluate the impact

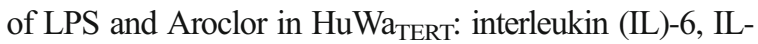
$1 \beta$, C-X-C motif chemokine ligand 10 (CXCL10), heat shock protein 70 (HSP70) and interferon (IFN)- $\gamma$.

Prior to analysis, cells were washed twice with $1 \times$ PBS $\left(4{ }^{\circ} \mathrm{C}\right)$ and lysed in $200 \mu \mathrm{l} 1 \times$ cell lysis buffer (RayBiotech, GA, USA) containing $1 \times$ protease inhibitor concentrate. Cells were re-suspended by pipetting on ice, incubated for $30 \mathrm{~min}$ at $4{ }^{\circ} \mathrm{C}$, followed by centrifugation $\left(14,000 \times \mathrm{g}, 10 \mathrm{~min}, 4^{\circ} \mathrm{C}\right)$. Cell lysates were stored at $-80{ }^{\circ} \mathrm{C}$ until analysis. Before the application of ELISA kits, the protein content was assessed with a bicinchoninic acid (BCA) protein assay kit (Pierce, Rockford, USA) following the instructions of the manufacturer, and added protein contents were adjusted to $1000 \mu \mathrm{g} / \mathrm{ml}$ total protein.

ELISA kits for human IL-6, IL-1 $\beta$ and IFN- $\gamma$ were purchased from Qiagen (Hombrechtikon, Switzerland), those for human CXCL10 and HSP70 were ordered from Invitrogen (Basel, Switzerland) and for $\mathrm{TNF} \alpha$ from RayBiotech (GA, USA). Quantitative assessment of the respective proteins was conducted according to the manufacturer's protocols. Briefly, cell lysates were incubated overnight at $4{ }^{\circ} \mathrm{C}$ with the respective immobilised antibody, followed by incubation with biotinylated antibody and HRP/streptavidin. The absorbance of the complex was assessed at $450 \mathrm{~nm}$ using the Tecan fluorescence plate reader. The limit of quantification was $21.4 \mathrm{pg} / \mathrm{ml}$ (TNF $\alpha), 14.0 \mathrm{pg} / \mathrm{ml}$ (IL-6), $16 \mathrm{pg} /$ $\mathrm{ml}$ (IL-1 $\beta), 2.0 \mathrm{ng} / \mathrm{ml}$ (HSP70), $31.3 \mathrm{pg} / \mathrm{ml}$ (IFN- $\gamma$ ) and $2.0 \mathrm{pg} / \mathrm{ml}$ (CXCL10).

\section{Assessment of inflammatory response to chemical exposure}

Stimulation experiments were carried out with LPS from E. coli 055:B5 (Sigma-Aldrich, Buchs,
Switzerland). LPS was dissolved in deionised nanopure water and applied by direct dosing into respective wells; cell viability was assessed at $0.1,1,10,25,50$ and $100 \mu \mathrm{g} / \mathrm{ml}$, and for immune stimulation, a non-cytotoxic concentration (ntC) of $10 \mu \mathrm{g} / \mathrm{ml}$ was selected.

For Aroclor exposure, a stock solution of Aroclor $(20 \mathrm{mg} / \mathrm{ml})$ was prepared in dimethyl sulfoxide (DMSO). Final nominal concentrations (100, 600, $1250,2500,5000,7500$ and 50,000 $\mu \mathrm{g} / \mathrm{l})$ were achieved by adding $32.5 \mu \mathrm{l}$ of the appropriate Aroclor concentration into $13 \mathrm{ml}$ of exposure medium (DMEM/F12; $1 \%$ FBS; $0.25 \%$ DMSO) using amber vials. Subsequently, $2 \mathrm{ml}$ of the final Aroclor concentration was added to respective wells of the 12 -well plate. To assess the impact of Aroclor on the inflammatory cytokines (as listed in "Quantification of inflammatory cytokines" section), a non-cytotoxic concentration (ntC) of $1700 \mu \mathrm{g} / \mathrm{l}$ was applied. All plates were covered with aluminium foil and cells were exposed at $37{ }^{\circ} \mathrm{C}$ with constant shaking at $250 \mathrm{rpm}$ for $24 \mathrm{~h}$. Immune treatment experiments were conducted with $\mathrm{HuWa}_{\mathrm{TERT}}$ cells of passages 35-42.

\section{Data and statistical analysis}

The data shown represent the mean of three independent biological replicates with cells from different passages unless indicated otherwise. Error bars represent standard deviation (SD) unless otherwise stated. Statistical differences were assessed for the LPS and Aroclor treatments by comparing the mean of the three independent experiments for each treatment and the unexposed control using a one-way ANOVA with Bonferroni's post hoc test; $p<0.05$ was considered as significant. The analysis was done using GraphPad Prism Version 7 (La Jolla, CA, USA). The noncytotoxic concentration (ntC) of Aroclor was identified as described by Stadnicka-Michalak et al. (2017).

\section{Results}

Transfection and characterisation of the new strain: $\mathrm{HuWa}_{\text {TERT }}$

$\mathrm{HuWa}_{\text {wild-type }}$ cells were transfected with plasmids containing either SV40T or hTERT. The two tested transfection reagents, Fugene and Lipofectamine, were both suitable to transfect $\mathrm{HuWa}_{\text {wild-type }}$ After transfection, 
antibiotic selection was applied with the first resistant cells appearing after $\approx 7$ days (Fig. S3). All three plasmids (pBABE-puro-SV40 LT, pBABE-puro-hTERT and pCEP4-hygro-SV40-Tg) were successfully transfected into $\mathrm{HuWa}_{\text {wild-type }}$ (Table S3).

In order to assess whether each of the SV40T plasmids (pBABE-puro-SV40 LT; pCEP4-hygroSV40-Tg) had been successfully introduced, and were also functional, the expression of SV40T was assessed in SV40T-transfected clones $\left(\mathrm{HuWa}_{\mathrm{SV} 40 \mathrm{~T}}\right)$. Nuclear SV40T immunostaining was detected in only a few cell nuclei for each of the plasmids (Fig. S4). Post-transfection, $\mathrm{HuWa}_{\mathrm{SV} 40 \mathrm{~T}}$ clones divided vigorously for 4-5 days, followed by gradually decreasing proliferation rates and a maximum life span of 15 passages, while most clones had ceased to proliferate at earlier passages. Further, cells increased in size and appeared more polygonal, rather than fusiform, in shape. This behaviour was observed for both SV40T containing plasmids.

In contrast, cells transfected with TERT continued to proliferate at an increased rate compared to $\mathrm{HuWa}_{\text {wild- }}$ type. When split 1:3, HuWa $\mathrm{T}_{\mathrm{TERT}}$ formed confluent cell monolayers within 1 week (Fig. 1a-c). Cells exhibited similar attachment efficiencies as $\mathrm{HuWa}_{\text {wild-type. The }}$ population doubling time during the log-growth phase was $25 \mathrm{~h}$ (Fig. 1d), compared to $41 \mathrm{~h}$ for $\mathrm{HuWa}_{\text {wild-type }}$. Karyotyping of HuWa $\mathrm{TERT}_{\mathrm{TER}}$ (P12, post-transfection) indicated 21 pairs of autosomes and 1 pair of male sex chromosomes, with no obvious structural abnormalities. Cells exhibited chromosome numbers approaching tetraploidy (Fig. 1e).

To test if TERT transfection was successful, $\mathrm{HuWa}_{\text {TERT }}$ cells were tested for their capacity to express telomerase. All tested passages showed positive telomerase expression, which was also stable over time (Fig. 1f). HuWa $\mathrm{w}_{\text {wild-type }}$ exhibited only baseline activity which was slightly higher than the limit of detection (dotted line in Fig. 1f, close to the X-axis).

SEM and confocal microscopy revealed abundant lipid bodies, between 0.5 and $1 \mu \mathrm{m}$ in diameter, within the outer cytoplasm (Fig. $1 \mathrm{~g} / \mathrm{h}$ ). The endoplasmic reticulum, which is typically quite distinctive in fibroblasts, was very abundant.

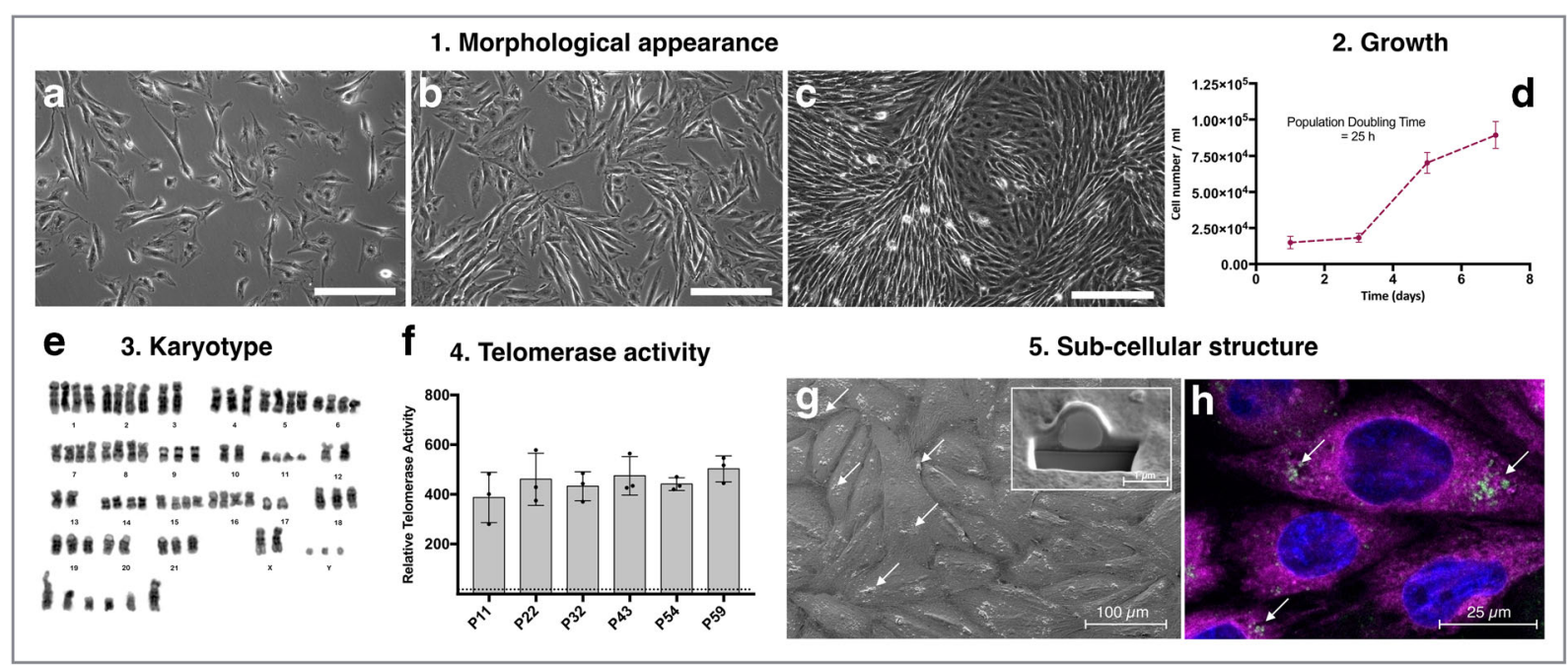

Fig. 1 Characterisation of the new strain: HuWa TERT. TERTtransfected cells were characterised for five different features. For morphological appearance (1), HuWa $\mathrm{T}_{\text {TERT }}$ cells were cultivated over time and the morphological appearance at different levels of confluency were assessed after 1 day (a), 3 days (b) and 7 days (c). Growth (2) was estimated as cell numbers at 1, 3,5 and 7 days after plating and the population doubling time calculated during the log phase (d). For the karyotype (3), chromosomes of $\mathrm{HuWa}_{\mathrm{TERT}}$ cells were visualised by G-banding; chromosome pairs of autosomes (1-21), sex chromosomes $(\mathrm{X}, \mathrm{Y})$ and unidentified chromosomes are displayed (e). The expression of telomerase (4) was measured in $\mathrm{HuWa}_{\mathrm{TERT}}$ cells at different passages post-transfection $(\mathbf{F})$. Data represent the mean of three technical replicates, and the error bars represent the SD for 10,000 cell equivalents. Sub-cellular structures (5) of cells were visualised by SEM (G); the inset shows a cross section of one intracellular lipid body. Arrows indicate lipid bodies as seen by confocal microscopy (H, green and arrows). Other sub-cellular structures visualised are the endoplasmic reticulum (magenta) and cell nucleus (blue) 
Expression of inflammatory cytokines in immune or chemically challenged $\mathrm{HuWa} \mathrm{a}_{\mathrm{TERT}}$

The presence, and concentrations, of the selected inflammatory cytokines was first tested in unstimulated cells. The inflammatory cytokines (IL-6, IL-1 $\beta$ and $\mathrm{TNF} \alpha$ ), inflammatory chemokine CXCL10 and the general stress marker HSP70 were selected based on the following criteria: expression in fibroblasts, reaction to LPS and response to immunotoxic chemicals (Fig. S5). All three cytokines and HSP70 were detected in unstimulated cell extracts: IL-6 $(\sim 307 \mathrm{pg} / \mathrm{ml}), \mathrm{TNF} \alpha(\sim$ $6 \mathrm{ng} / \mathrm{ml}), \mathrm{IL}-1 \beta(\sim 27 \mathrm{pg} / \mathrm{ml})$ and HSP70 $(\sim 250 \mathrm{ng} / \mathrm{ml})$. CXCL10 and IFN- $\gamma$ were not present at detectable levels in $\mathrm{HuWa}_{\mathrm{TERT}}$ cells. The expression of cytokines was independent from the passage number of $\mathrm{HuWa}_{\text {TERT }}$; experiments with earlier passages (P 1825) resulted in comparable results.

Before the treatment with LPS or Aroclor, noncytotoxic concentrations (ntC) were ascertained by cell viability assessment. LPS can trigger expression of inflammatory cytokines at various concentrations; however, high concentrations result in cellular toxicity. LPS treatment of 100 and $50 \mu \mathrm{g} / \mathrm{ml}$ clearly reduced metabolic activity of HuWa $\mathrm{TERT}_{\mathrm{TER}}$, while concentrations $\leq$ $10 \mu \mathrm{g} / \mathrm{ml}$ were comparable to the LPS-free control (Fig. 2A1). Exposure to Aroclor also indicated a concentration-dependent cytotoxicity, with a higher reduction of cell viability being observed for membrane integrity $\left(\mathrm{EC}_{50}=7.45 \mathrm{mg} / \mathrm{l}\right)$ compared to metabolic activity $\left(\mathrm{EC}_{50}=23.14 \mathrm{mg} / \mathrm{l}\right)$ (Fig. 2B2). The stimulation challenge with LPS and the chemical challenge upon Aroclor exposure were performed with the noncytotoxic concentrations of $10 \mu \mathrm{g} / \mathrm{ml}$ (LPS) and $1700 \mu \mathrm{g} / \mathrm{l}$ (Aroclor). For both challenges, the expression of inflammatory cytokines (IL- $1 \beta$, IL- 6, TNF $\alpha$ and HSP70) was not significantly different from levels in unstimulated cells. The cytokines, CXCL10 and IFN- $\gamma$, were not detectable in challenged HuWa $\mathrm{TERT}_{\mathrm{TER}}$ cells.

\section{Discussion}

This study was designed to develop a consistent in vitro model to ensure long-term preservation of HuWa cell lines, and apply this model to bridge knowledge gaps regarding the immune health of humpback whales, in particular by assessment of sub-cellular responses under immune stimulation and chemical stress.
$\mathrm{HuWa}_{\text {wild-type }}$ cells were successfully transfected with TERT leading to the establishment of a new strain, HuWa $a_{\text {TERT. Accordingly, telomerase activity was }}$ measureable and stable over at least 59 passages. By contrast, only baseline telomerase activity was found in $\mathrm{HuWa}_{\text {wild-type }}$ cells. This activity is in line with observed telomerase values in fibroblasts of grey whales (Eschrichtius robustus) and fibroblasts of bowhead whales (Balaena mysticetus) (Gorbunova and Seluanov 2009). According to population doubling times (PBT), $\mathrm{HuWa}_{\text {TERT }}$ proliferate more rapidly $(25 \mathrm{~h})$ than $\mathrm{HuWa}_{\text {wild-type }}(41 \mathrm{~h})$ (Burkard et al. 2015). The cells display the typical elongated, bipolar and spindleshaped fibroblast morphology observed in $\mathrm{HuWa}_{\text {wild-type. }}$ Karyotyping revealed that $\mathrm{HuWa}_{\text {TERT }}$ cells have normal chromosome numbers and structures; however, cells showed tetraploidy which is a commonly observed artefact in cultured cell lines (Leibiger et al. 2013).

The transfection efficiencies of both SV40T plasmids were low, and transient, since very few cells expressed the SV40T protein and, while proliferation rates were initially high, most cells ceased proliferating after just a few passages. SV40T transformation is often associated with non-consistent transfection, genomic variability and changed morphology (Ouellette et al. 2000; Mayne et al. 1986). Indeed, long-term SV40T expression in mammalian cells is relatively rare; it is often reached only together with telomerase activation (Foddis et al. 2002; Li et al. 2008).

By contrast, TERT transfection resulted in clones that divided vigorously, and revealed no distinctive morphological changes or signs of senescence. A non-malignant phenotype, physiological stability (Jiang et al. 1999; Morales et al. 1999) and higher resistance towards DNA damage (Sherr and DePinho 2000) are the major advantages of TERT transfections. Thus far in our studies, $\mathrm{HuWa}_{\text {TERT }}$ was sub-cultured for 71 passages (12 times prior and 59 times post-transfection), which corresponds to $\sim 107$ population doublings, assuming 1.5 generations per passage. In un-transformed lung fibroblasts of the bowhead whale, growth arrest was observed after 86 population doublings (Gorbunova and Seluanov 2009). With the long-term preservation, HuWa $\mathrm{T}_{\mathrm{TERT}}$ are a promising, low-cost and easy-to-use resource for fundamental marine wildlife research to advance our current understanding of species-specific physiological responses. Application of cell-based studies can help to identify cellular mechanisms and targets of environmental stressors, such as chemical pollutants, harmful algal toxins and emerging pathogens. 


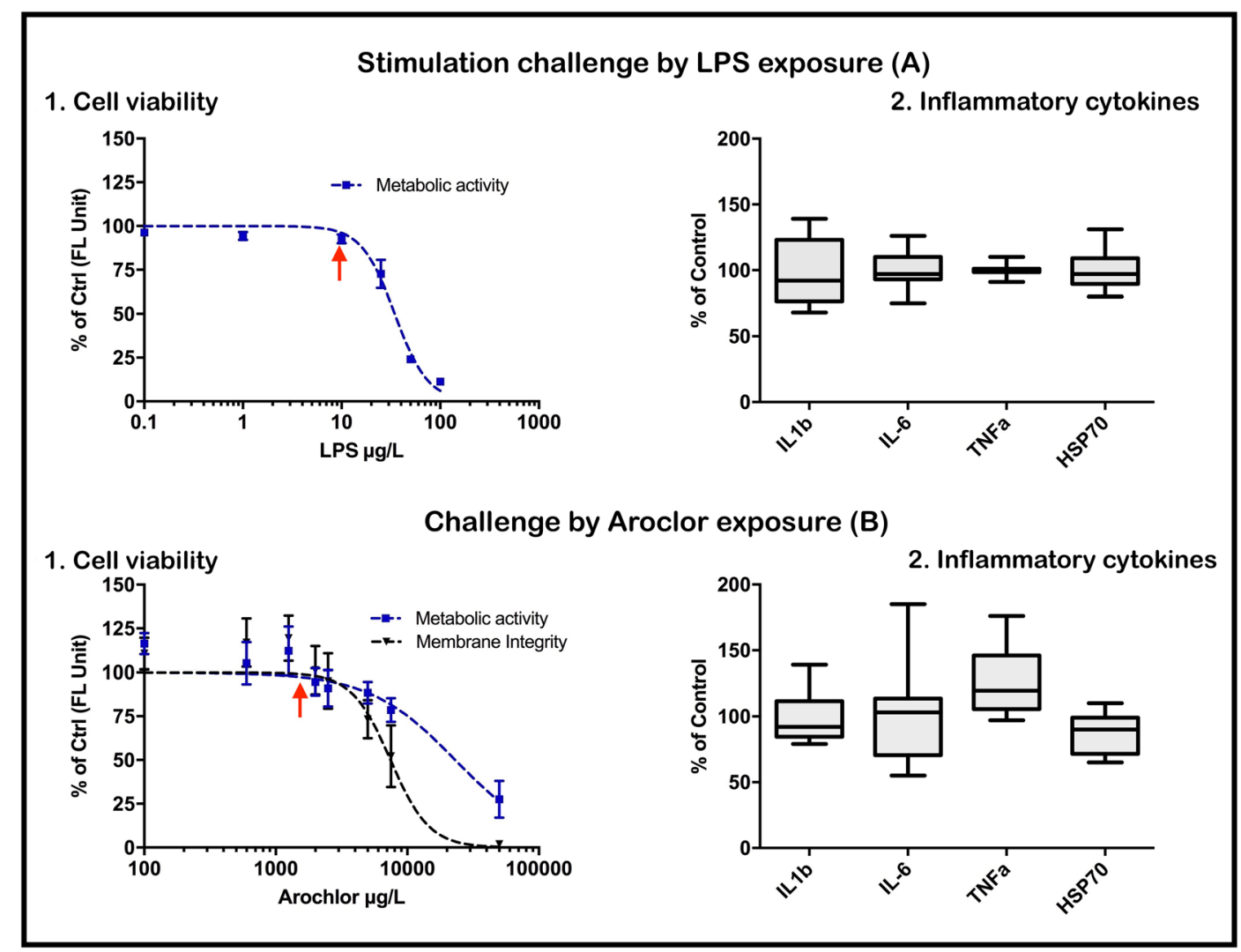

Fig. 2 Expression of inflammatory cytokines in $\mathrm{HuWa}_{\mathrm{TERT}}$ either stimulated with LPS or exposed to Aroclor. For cell viability assessment, HuWa $\mathrm{TERT}_{\text {TEl }}$ cells were treated with different LPS (A.1) and Aroclor (B.1) concentrations. After $24 \mathrm{~h}$ of exposure, metabolic activity using AlamarBlue (LPS and Aroclor) and membrane integrity using CFDA-AM (Aroclor only) were measured. The data in A.1 represents the mean of three technical and, B.1, three biological replicates; the error bars represent SD and are shown as percentage of non-treated cells. The cellular expression

Dermal fibroblasts are immune-active cells and are both targeted by, and actively react to, immune stimulation (Apte 1995; Korn 1997). Fibroblasts can be stimulated in order to express a wide range of different signalling proteins such as cytokines (Van Linthout et al. 2014; Buckley et al. 2001). In this study, the levels of inflammatory cytokines were assessed in immunestimulated and chemically stressed cells of the new $\mathrm{HuWa}_{\mathrm{TERT}}$ strain. IL-6, IL-1 $\beta$, TNF $\alpha$ and HSP70 were constitutively expressed in HuWa $\mathrm{TERT}_{\mathrm{TER}}$, while CXCL10 and IFN- $\gamma$ were not detected with, or without, stimulation/chemical stress. Quantification of the tested cytokines was performed by ELISA which is dependent on successful antibody-target protein reaction. All positively expressed proteins were based on cross-reaction of selected inflammatory cytokines (IL- $1 \beta, \mathrm{IL}-6, \mathrm{TNF} \alpha$ and HSP70) was measured upon treatment with non-cytotoxic concentrations (indicated by red arrow) of LPS $(10 \mu \mathrm{g} / \mathrm{ml})$ (A.2) or Aroclor $(1700 \mu \mathrm{g} / \mathrm{l})(\mathrm{B} .2)$ for $24 \mathrm{~h}$. The data is shown as percentage of control. Boxplots indicate median, 5 and 95 percentiles and $\mathrm{min} / \mathrm{max}$ of three independent biological replicates. No statistical difference was found between single markers and unexposed control using one-way ANOVA and Bonferroni's post hoc test $(p<0.05)$

with mammalian antibodies. In general, activity of cytokines and chemokines is relatively well conserved throughout evolution (Kimbrell and Beutler 2001; Secombes et al. 2016; Zou et al. 2016; Zlotnik et al. 2006). The high cross-reactivity of mammalian antibodies with HuWa $\mathrm{T}_{\text {TERT }}$ further alludes to the potential of antibody-based methodologies for immune and proteinbased biomarker studies. One possible approach is to apply blubber extracts as an environmentally afflicted tissue and use extended cytokine-based immune screening for a better understanding of specific stress responses, such as local inflammation or wound healing.

Cellular responses upon immune stimulation are complex and differ between different stressors. As such, LPS generally mimics bacterial infections by triggering 
immune and physiological reactions, in particular the regulation of cytokine levels (Alexander and Rietschel 2001). We investigated the expression of inflammatory markers in $\mathrm{HuWa}_{\mathrm{TERT}}$ upon treatment with a noncytotoxic concentration of LPS, which did not result in a significant upregulation of IL-6, IL- $1 \beta, \mathrm{TNF} \alpha$ and HSP70. For IL- 6 and IL- $1 \beta$, distinctive upregulation upon LPS stimulation is reported for human fibroblasts (Table S2) suggesting the possibility of a similar response in $\mathrm{HuWa}_{\mathrm{TERT}}$ cells. However, sensitivity towards LPS is highly species and cell type specific. In human fibroblasts, the ability to regulate cytokines was greatly dependent on the fibroblast type (e.g. wound vs. normal tissue) or differentiation state of fibroblasts (Fibbe et al. 1988; Seelentag et al. 1989; Damme et al. 1989). Further, we tested the effect of different concentrations of LPS, in addition to LPS derived from different species of bacteria. Treatment with different concentrations of LPS $(0.1,1,10 \mu \mathrm{g} / \mathrm{ml})$ and LPS from a different species (Pseudomonas aeruginosa) or LPS from a different E. coli batch (E. coli 0111:B4) did not result in upregulation of IL-6 and TNF $\alpha$ expression (Fig. S5). Thus, our findings suggest that $\mathrm{HuWa}_{\mathrm{TERT}}$ are less sensitive towards LPS compared to human dermal fibroblasts. Besides LPS, other stimulants, such as ovalbumin (a T cell-dependent antigen), concanavalin A (a lymphocyte mitogen) or a virus-based stimulus (poly(I:C)), may be tested to investigate immune regulation in HuWaTERT, comprising future avenues of investigation; one commonly observed pathogen, for example, is the cetacean morbillivirus (CeMV). This virus infects specifically whales, dolphins and porpoise, and several mass mortality events of infected populations have been linked to CeMV epidemics (Van Bressem et al. 2014).

PCBs have been observed to have an immunotoxic impact on marine mammals (Desforges et al. 2016; Mori et al. 2008; Desforges et al. 2017) and were therefore selected as the second applied stressor in this study. Cell viability measurement revealed a lower $\mathrm{EC}_{50}$ value for the PCB mixture Aroclor towards membrane integrity, compared to metabolic activity, suggesting perturbation of membranes upon PCB exposure. PCBs are able to cross lipid layers (ATSDR 2000), and, in southern hemisphere humpback whales, PCBs accumulate in the adipose tissue in the range of $\Sigma \mathrm{PCB}_{32}<\mathrm{LOD}$ to $720 \mathrm{ng} / \mathrm{g}_{\text {lipid }}$ (average $\sim 20 \mathrm{ng} / \mathrm{g}_{\text {lipid }}$ ) (Bengtson Nash et al. 2013; Waugh et al. 2014; Bengtson Nash et al. 2018). If applying a blubber-to-blood diffusion of $0.05 \%$
(Cropp et al. 2014) and a blood density of $1.03 \mathrm{~g} /$ $\mathrm{cm}^{3}$, the estimated blood concentration of PCBs in humpback whales is $9.3 \mathrm{pg} / \mathrm{ml}$. In this study, $\mathrm{HuWa}_{\text {TERT }}$ were exposed to $1722 \mathrm{ng} / \mathrm{ml}$ Aroclor, but no alterations of IL- 6 , IL- $1 \beta$, TNF $\alpha$ and HSP70 levels were detectable. No humpback whale study reports the impact of PCBs on these cytokines, and only a few studies have investigated this in marine mammals. In seals with elevated PCB concentrations in their tissue, a correlation between IL-1 $\beta$ levels and increasing PCB concentrations was found (Brown et al. 2014; Routti et al. 2010); on the contrary, in vitro suppressive effects were detected when measuring IL-1 $\beta$ mRNA levels in seal leukocytes (Neale et al. 2005). There is no information about the influence of PCBs on IL- 6 , TNF $\alpha$ and HSP70 regulation in marine mammals. In humans with elevated PCB concentrations in blood (31-1025 ng/l), no impact was found on IL-6 regulation in human lymphocytes (Daniel et al. 2001). Further, in vitro studies revealed reduced TNF $\alpha$ mRNA levels in murine macrophages upon exposure to PCBs (Santoro et al. 2015), and no change was detected in PCB-exposed human mast cells (Kwon et al. 2002).

Based on the results of this study and the mammalian studies discussed above, there are still significant knowledge gaps regarding the understanding of immune regulation, particularly in combination with exposure to chemicals in marine mammals. The development of the new $\mathrm{HuWa}_{\text {TERT }}$ strain provides sufficient material for extensive analyses, and is a promising alternative to address these gaps to gain insights in the unique physiological adaptations and molecular responses of humpback whales.

\section{Conclusion}

We demonstrated successful transfer of an exogenous gene into humpback whale fibroblasts. Stable telomerase expression suggests that this cell line can be maintained long term. The positive expression of selected inflammatory cytokines (IL-6, IL$1 \beta$, TNF $\alpha$ and HSP70) demonstrates the applicability of this cell line for further immunological and physiological investigations. Overall, it opens manifold opportunities to study humpback whalespecific characteristics and cellular response mechanisms. 
Acknowledgements Michael Burkard acknowledges a $\mathrm{PhD}$ scholarship from Griffith University.

Funding information This project was funded by a Pacific Life Ocean Foundation grant.

Open Access This article is distributed under the terms of the Creative Commons Attribution 4.0 International License (http:// creativecommons.org/licenses/by/4.0/), which permits unrestricted use, distribution, and reproduction in any medium, provided you give appropriate credit to the original author(s) and the source, provide a link to the Creative Commons license, and indicate if changes were made.

Publisher's Note Springer Nature remains neutral with regard to jurisdictional claims in published maps and institutional affiliations.

\section{References}

Ahuja D, Saenz-Robles MT, Pipas JM. SV40 large T antigen targets multiple cellular pathways to elicit cellular transformation. Oncogene. 2005;24:7729-45.

Alexander C, Rietschel ET. Bacterial lipopolysaccharides and innate immunity. J Endotoxin Res. 2001;7:167-202.

Ali SH, Decaprio JA. Cellular transformation by SV40 large T antigen: interaction with host proteins. Semin Cancer Biol. 2001;11:15-22.

Apprill A, Robbins J, Eren AM, Pack AA, Reveillaud J, Mattila D, et al. Humpback whale populations share a core skin bacterial community: towards a health index for marine mammals? PLoS One. 2014;9:e90785.

Apte RN. Mechanisms of cytokine production by fibroblastsimplications for normal connective tissue homeostasis and pathological conditions. Folia Microbiol. 1995;40:392-404.

ATSDR. Toxicological profile for polychlorinated biphenyls (PCBs). In: Services, U. S. D. O. H. A. H. \& Registry, A. F. T. S. A. D. (eds.). Atlanta, Georgia 30333; 2000.

Bengtson Nash S. Toxicological risks and considerations associated with lipophilic contaminant burdens of Southern Ocean Mysticetes. In: Fossi C \& Panti C, editors. Marine Mammal Ecotoxicology: impacts of multiple stressors on population health. 1st ed. Elsevier; 2018

Bengtson Nash SM, Waugh CA, Schlabach M. Metabolic concentration of lipid soluble organochlorine burdens in humpback whales through migration and fasting. Environ Sci Technol. 2013;47:9404-13.

Bengtson Nash SM, Waugh CA, Burkard M, Dawson A, Huston W. Detoxification enzyme activities (CYP1A1 and GST) in the skin of humpback whales as a function of organochlorine burdens and migration status. Aquat Toxicol. 2014;155:20712.
Bengtson Nash S, Castrillon J, Eisenmann P, Fry B, Shuker J, Cropp R, et al. Signals from the south; humpback whales carry messages of Antarctic Sea-ice ecosystem variability. Glob Chang Biol. 2018;24:1500-10.

Bodnar AG, Ouellette M, Frolkis M, Holt SE, Chiu C-P, Morin $\mathrm{GB}$, et al. Extension of life-span by introduction of telomerase into normal human cells. Science. 1998;279:349-52.

Brown TM, Ross PS, Reimer KJ, Veldhoen N, Dangerfield NJ, Fisk AT, et al. PCB related effects thresholds as derived through gene transcript profiles in locally contaminated ringed seals (Pusa hispida). Environ Sci Technol. 2014;48: 12952-61.

Buckley CD, Pilling D, Lord JM, Akbar AN, Scheel-Toellner D, Salmon M. Fibroblasts regulate the switch from acute resolving to chronic persistent inflammation. Trends Immunol. 2001;22:199-204.

Burkard M, Whitworth D, Schirmer K, Nash SB. Establishment of the first humpback whale fibroblast cell lines and their application in chemical risk assessment. Aquat Toxicol. 2015;167: 240-7.

Cropp R, Bengtson Nash SM, Hawker D. A model to resolve the dynamics of organochlorine pharmacokinetics in migrating humpback whales. Environ Toxicol Chem. 2014;33:163849.

Damme JV, Ronald Schaafsma M, Fibbe WE, Frederik Falkenburg J, Opdenakker G, Billiau A. Simultaneous production of interleukin 6 , interferon- $\beta$ and colony-stimulating activity by fibroblasts after viral and bacterial infection. Eur J Immunol. 1989;19:163-8.

Daniel V, Huber W, Bauer K, Suesal C, Conradt C, Opelz G. Associations of blood levels of PCB, HCHS, and HCB with numbers of lymphocyte subpopulations, in vitro lymphocyte response, plasma cytokine levels, and immunoglobulin autoantibodies. Environ Health Perspect. 2001;109:173-8.

Desforges J-PW, Sonne C, Levin M, Siebert U, De Guise S, Dietz R. Immunotoxic effects of environmental pollutants in marine mammals. Environ Int. 2016;86:126-39.

Desforges J-P, Levin M, Jasperse L, De Guise S, Eulaers I, Letcher RJ, et al. Effects of polar bear and killer whale derived contaminant cocktails on marine mammal immunity. Environ Sci Technol. 2017;51:11431-9.

Di Leonardo A, Linke SP, Clarkin K, Wahl GM. DNA damage triggers a prolonged $\mathrm{p} 53$-dependent $\mathrm{G} 1$ arrest and long-term induction of Cip1 in normal human fibroblasts. Genes Dev. 1994;8:2540-51.

Fibbe WE, Van Damme J, Billiau A, Duinkerken N, Lurvink E, Ralph $\mathrm{P}$, et al. Human fibroblasts produce granulocyte-CSF, macrophage-CSF, and granulocyte-macrophage-CSF following stimulation by interleukin-1 and poly (rI). Poly (rC). Blood. 1988;72:860-6.

Foddis R, De Rienzo A, Broccoli D, Bocchetta M, Stekala E, Rizzo P, et al. SV40 infection induces telomerase activity in human mesothelial cells. Oncogene. 2002;21:1434-42.

Gorbunova V, Seluanov A. Coevolution of telomerase activity and body mass in mammals: from mice to beavers. Mech Ageing Dev. 2009;130:3-9. 
Hayflick L. The limited in vitro lifetime of human diploid cell strains. Exp Cell Res. 1965;37:614-36.

He Z, Zhu Y, Jiang H. Toll-like receptor 4 mediates lipopolysaccharide-induced collagen secretion by phosphoinositide3-kinase-Akt pathway in fibroblasts during acute lung injury. J Recept Signal Transduction. 2009;29: 119-25.

Holyoake C, Stephens N, Coughran D. Collection of baseline data on humpback whale (Megaptera novaeangliae) health and causes of mortality for long-term monitoring in Western Australia. Conservation Medicine Program, School of Veterinary and Biomedical Sciences, Murdoch University; Nature Protection Branch, Department of Environment and Conservation, Government of Western Australia; 2012

Jiang X-R, Jimenez G, Chang E, Frolkis M, Kusler B, Sage M, et al. Telomerase expression in human somatic cells does not induce changes associated with a transformed phenotype. Nat Genet. 1999;21:111-4.

Jin W, Jia KT, Yang LL, Chen JL, Wu YP, Yi MS. Derivation and characterization of cell cultures from the skin of the indoPacific humpback dolphin Sousa chinensis. In Vitro Cell Dev Biol Anim. 2013;49:449-57.

Kimbrell DA, Beutler B. The evolution and genetics of innate immunity. Nat Rev Genet. 2001;2:256-67.

Korn J. Fibroblast function and fibrosis. Textbook of rheumatology. Philadelphia: WB Saunders; 1997. p. 199-230.

Kwon O, Lee E, Moon TC, Jung H, Lin CX, Nam K-S, et al. Expression of cyclooxygenase-2 and pro-inflammatory cytokines induced by $2,2^{\prime}, 4,4^{\prime}, 5,5^{\prime}$-hexachlorobiphenyl (PCB 153 ) in human mast cells requires NF- $\mathrm{KB}$ activation. Biol Pharm Bull. 2002;25:1165-8.

Leibiger C, Kosyakova N, Mkrtchyan H, Glei M, Trifonov V, Liehr T. First molecular cytogenetic high resolution characterization of the NIH 3T3 cell line by murine multicolor banding. J Histochem Cytochem. 2013;61:306-12.

Levin M, Romano T, Matassa K, De Guise S. Validation of a commercial canine assay kit to measure pinniped cytokines. Vet Immunol Immunopathol. 2014;160:90-6.

Li L, Willimsky G, Seitz S, Xu Y, Li Y, Schwarz LE, et al. SV40 large $\mathrm{T}$ antigen-transformed human primary normal and cancerous mammary epithelial cells are phenotypically similar but can be distinguished in 3D culture with selection medium. Int J Cancer. 2008;123:1516-25.

Mayne LV, Priestley A, James MR, Burke JF. Efficient immortalization and morphological transformation of human fibroblasts by transfection with SV40 DNA linked to a dominant marker. Exp Cell Res. 1986;162:530-8.

Morales CP, Holt SE, Ouellette M, Kaur KJ, Yan Y, Wilson KS, et al. Absence of cancer-associated changes in human fibroblasts immortalized with telomerase. Nat Genet. 1999;21: 115-8.

Mori C, Morsey B, Levin M, Gorton TS, De Guise S. Effects of organochlorines, individually and in mixtures, on B-cell proliferation in marine mammals and mice. $\mathrm{J}$ Toxicol Environ Health A. 2008;71:266-75.
Nakagawa H, Opitz OG. Inducing cellular senescence using defined genetic elements. Methods Mol Biol. 2007;371:16778.

Neale JCC, Kenny TP, Tjeerdema RS, Gershwin ME. PAH- and PCB-induced alterations of protein tyrosine kinase and cytokine gene transcription in harbor seal (Phoca Vitulina) PBMC. Clin Dev Immunol. 2005;12:91-7.

Ouellette MM, Mcdaniel LD, Wright WE, Shay JW, Schultz RA. The establishment of telomerase-immortalized cell lines representing human chromosome instability syndromes. Hum Mol Genet. 2000;9:403-11.

Pine M, Schroeder M, Greer K, Hokanson R, Busbee D. Generation and partial characterization of a transformed cetacean cell line. Aquat Toxicol. 2004;67:195-202.

Routti H, Arukwe A, Jenssen BM, Letcher RJ, Nyman M, Backman C, et al. Comparative endocrine disruptive effects of contaminants in ringed seals (Phoca hispida) from Svalbard and the Baltic Sea. Comp Biochem Physiol C Toxicol Pharmacol. 2010;152:306-12.

Santoro A, Ferrante MC, Di Guida F, Pirozzi C, Lama A, Simeoli R, et al. Polychlorinated biphenyls (PCB 101, 153, and 180) impair murine macrophage responsiveness to lipopolysaccharide: involvement of NF-kappaB pathway. Toxicol Sci. 2015;147:255-69.

Schirmer K, Chan AGJ, Greenberg BM, Dixon DG, Bols NC. Methodology for demonstrating and measuring the photocytotoxicity of fluoranthene to fish cells in culture. Toxicol in Vitro. 1997;11:107-19.

Secombes CJ, Wang T \& Bird S. Chapter 5-vertebrate cytokines and their evolution A2 - Malagoli, Davide. The Evolution of the Immune System. Academic Press; 2016

Seelentag W, Mermod JJ, Vassalli P. Interleukin 1 and tumor necrosis factor- $\alpha$ additively increase the levels of granulocyte-macrophage and granulocyte colonystimulating factor (CSF) mRNA in human fibroblasts. Eur J Immunol. 1989;19:209-12.

Sherr CJ, Depinho RA. Cellular senescence: minireview mitotic clock or culture shock? Cell. 2000;102:407-10.

Stadnicka-Michalak J, Knobel M, Zupanic A, Schirmer K. A validated algorithm for selecting non-toxic chemical concentrations. ALTEX. 2017.

Van Bressem M-F, Duignan PJ, Banyard A, Barbieri M, Colegrove KM, De Guise S, et al. Cetacean morbillivirus: current knowledge and future directions. Viruses. 2014;6: 5145-81.

Van Linthout S, Miteva K, Tschöpe C. Crosstalk between fibroblasts and inflammatory cells. Cardiovasc Res. 2014;102: 258-69.

Vaziri H, Benchimol S. From telomere loss to p53 induction and activation of a DNA-damage pathway at senescence: the telomere loss/DNA damage model of cell aging. Exp Gerontol. 1996;31:295-301.

Wang J, Su W, Nie W, Wang J, Xiao W, Wang D. Establishment and characterization of fibroblast cell lines from the skin of the Yangtze finless porpoise. In Vitro Cell Dev Biol Anim. 2011;47:618-30. 
Waugh CA, Huston W, Noad M, Bengtson Nash SM. Cytochrome P450 isoenzyme protein verified in the skin of southern hemisphere humpback whales (Megaptera novaeangliae); implications for biochemical biomarker assessment. Mar Pollut Bull. 2011;62:75861.

Waugh CA, Nichols PD, Schlabach M, Noad M, Bengtson Nash SM. Vertical distribution of lipids, fatty acids and organochlorine contaminants in the blubber of southern hemisphere humpback whales (Megaptera novaeangliae). Mar Environ Res. 2014;94:24-31.

Wright WE, Shay JW. The two-stage mechanism controlling cellular senescence and immortalization. Exp Gerontol. 1992;27:383-9.
Wright WE, Pereira-Smith OM, Shay JW. Reversible cellular senescence: implications for immortalization of normal human diploid fibroblasts. Mol Cell Biol. 1989;9:3088-92.

Yu J, Kindy MS, Ellis BC, Baatz JE, Peden-Adams M, Ellingham TJ, et al. Establishment of epidermal cell lines derived from the skin of the Atlantic bottlenose dolphin (Tursiops truncatus). Anat Rec A Discov Mol Cell Evol Biol. 2005;287:1246-55.

Zlotnik A, Yoshie O, Nomiyama H. The chemokine and chemokine receptor superfamilies and their molecular evolution. Genome Biol. 2006;7:1-11.

Zou J, Castro R \& Tafalla C. Chapter 7-antiviral immunity: origin and evolution in vertebrates A2-Malagoli, Davide. The Evolution of the Immune System. Academic Press; 2016 